\title{
Studies on corrosion behaviour of sintered aluminium based composites in chloride environment
}

\author{
Samuel Olukayode Akinwamide*, Miltia Lesufi, Ojo Jeremiah Akinribide, Bukola Joseph Babalola, \\ and Peter Apata Olubambi \\ Center for Nanomechanics and Tribocorrosion, School of Metallurgy, Chemical and Mining Engineering, University \\ of Johannesburg, Johannesburg, South Africa
}

Received: 23 April 2021 / Accepted: 3 July 2021

\begin{abstract}
Aluminium matrix composites have been developed to replace other conventional engineering materials in specific industries where enhanced properties are required. The corrosion susceptibility of sintered unreinforced aluminium and composites in chloride medium (AMCs) were studied. The powders of pure asreceived aluminium (matrix) and particles of ferrotitanium and silicon carbide particles were homogeneously dispersed using ball milling technique. Powder metallurgy route was utilised for consolidating the milled powders into a sintered compact. Microstructural examination of the compacted pure aluminium and composites confirmed an even distribution of the reinforcements in the aluminium matrix. The produced composites also recorded an improved corrosion resistance in a corrosive medium of 3.5 wt.\% laboratory prepared sodium chloride, from the potentiodynamic polarization and chronoamperometry (potentiostatic) tests. The corroded specimens were further assessed for pitting using a field emission scanning electron microscope (FE-SEM). The resistance of the fabricated samples to corrosion was improved upon the addition of TiFe and SiC reinforcements.
\end{abstract}

Keywords: Ferrotitanium / spark plasma sintering / silicon carbide / aluminium matrix composites / corrosion

\section{Introduction}

Aluminium matrix composites (AMCs) are vastly used in several engineering sectors for different applications. The commonly used matrix used for the fabrication of these classes of composites includes aluminium, magnesium, titanium, and copper [1]. Aluminium has been widely used due to its outstanding properties, which include improved ductility, exceptional thermal and electrical properties $[2,3]$. This class of materials also possesses the ability to sustain its properties at extremely low temperatures. However, these properties can be enhanced by incorporating another reinforcement particle(s) into the aluminium matrix, thereby resulting in the production of composites that are aluminium based $[4,5]$.

The corrosion of aluminium and other metallic composites has been reported to be a significant challenge in manufacturing industries. Research has shown that the yearly loss and damage arising from corrosion in the United Kingdom, as an example, has been given to be approximately £ 5000 million [6]. However, this wasteful

\footnotetext{
* e-mail: akinwamidekayode@gmail.com
}

occurrence could be averted if factors such as proper material selection, correct design, and reinforcing of metallic matrixes with adequate reinforcement particles are carefully considered. Some specific corrosion problems associated with AMCs include but are not limited to porosity, micro-crevices, and galvanic coupling. Their significance depends on the choice of reinforcements and the processing route adopted during fabrication.

The selection of reinforcement used for enhancing the corrosion susceptibility of compacted AMCs has been a significant challenge, as different reinforcing particles will directly affect the corrosion properties of the resulting AMC [7]. Therefore, careful consideration must be put in place towards the selection of the suitable reinforcements. Commonly used particles include titanium nitride, titanium nitride, silicon carbide, titanium diboride, and alumina $[8,9]$. Further, the fabrication technique utilised for the fabrication of AMCs can affect the distribution of the TiFe and $\mathrm{SiC}$ in the matrix, thereby affecting the rate at which the composites resist corrosion.

Several methods, including casting, pressure infiltration, and additive manufacturing, exist for the fabrication of AMCs. However, the spark plasma sintering technique has become a common method of consolidation of admixed 
Table 1. Chemical composition of silicon carbide powder and ferrotitanium powders.

\begin{tabular}{llllllllllll}
\hline Elements & $\mathrm{Al}$ & $\mathrm{Ti}$ & $\mathrm{Mn}$ & $\mathrm{Fe}$ & $\mathrm{K}$ & $\mathrm{Ba}$ & $\mathrm{Ca}$ & $\mathrm{Mg}$ & $\mathrm{Cr}$ & $\mathrm{Ni}$ & $\mathrm{Si}$ \\
\hline $\mathrm{SiC}$ & 0.21 & 0.02 & - & 0.23 & 0.04 & 0.05 & 0.04 & 0.01 & - & 0.01 & 99.21 \\
$\mathrm{TiFe}$ & 0.36 & 41.67 & 0.07 & 56.55 & - & - & 0.03 & 0.09 & 0.03 & 0.11 & 0.56 \\
\hline
\end{tabular}

powders [10]. The powders are compacted after they are heated in a vacuum furnace below their melting points to allow diffusion of atoms present $[11,12]$. The corrosion behavior and microstructural properties of $\mathrm{SiC}$ reinforced AMCs produced using sintering technique were investigated in research conducted by Zakaria et al. [13]. The authors reported that the corrosion resistance of the compacted $\mathrm{Al} / \mathrm{SiC}$ samples was improved with a respective increase in the volume fraction of $\mathrm{SiC}$.

Another recent investigation by Akinwamide et al. [14] also reported on the corrosion susceptibility of $\mathrm{Al} / \mathrm{TiFe} / \mathrm{SiC}$ samples fabricated via casting route. The combination of $\mathrm{SiC}$ and $\mathrm{TiFe}$ recorded an improved corrosion property in comparison to other specimens. The enhanced corrosion resistance in these studies was attributed to the even distribution of the particles dispersed within the matrix. This present study presents the resistance of the $\mathrm{Al} / \mathrm{TiFe} / \mathrm{SiC}$ composites consolidated by spark plasma sintering technique to corrosion.

\section{Materials and methods}

The powders of pure aluminium (99\% pure), silicon carbide, and ferrotitanium powders with respective average particle size and mesh size of $7 \mu \mathrm{m}$ and 40 , were used for this investigation. The composition of the $\mathrm{TiFe}$ and $\mathrm{SiC}$ reinforcement powders is presented in Table 1. Different volume fractions of the reinforcement particles were dispersed within the pure aluminum matrix using highenergy ball milling. The proportion of powder to ball ratio and milling speed of 1:10 and 150 revolutions per minute (rpm) were used to achieve this purpose. The sintering process of the alloyed powders was carried out in a nitrogen atmosphere at a pressure and temperature of $50 \mathrm{MPa}$ and $550^{\circ} \mathrm{C}$, respectively. The milled powders were placed in $20 \mathrm{~mm}$ to ensure adequate densification of the sintered specimens. Electrochemical testing of the sintered specimens was analyzed using a VersaSTAT studio potentiostat which runs on a versa studio electrochemical software. Prior to the electrochemical test, the surface of the specimens was sectioned to a $10 \mathrm{~mm} \times 10 \mathrm{~mm}$ dimension and ground from 200 to 1000 grits using silicon carbide emery papers. The polishing of the ground surface was carried out using 6 and $3 \mu$ suspension on Aka Daran disc and diamond suspension on a polishing cloth. Potentiodynamic polarization and potentiostatic tests were used for assessing the susceptibility of the specimens to corrosion in 3.5 wt.\% sodium chloride electrolyte. This electrolyte provided the corrosive environment due to the presence of aggressive chloride ions, which causes rapid deterioration of metallic materials. The scanning potentials and scan rate for potentiodynamic polarization were maintained within the range of $-1.2 \mathrm{~V}$ and $0.9 \mathrm{~V}$ and $0.2 \mathrm{mV}$ respectively. Potentiostatic tests were also carried out for $7200 \mathrm{~s}$ using the potential obtained from the passivation curve in the potentiodynamic polarization test. The corroded specimens were further analyzed for pits formation using scanning electron microscopes.

\section{Results and discussion}

\subsection{Microstructural analysis}

Shown in Figure 1 is the optical micrograph of the sintered specimens, with different volume percent of $\mathrm{TiFe}$ and $\mathrm{SiC}$ reinforcements. The inclusion of these reinforcements shows a significant effect on the microstructural evolution of the specimens [11]. Well-defined grains and little pores at intergranular regions are evident in the microstructure of the pure aluminium as shown in Figure 1a. In contrast, Figure 1b-d shows a uniform distribution of reinforcement between the aluminium grains. It is also observed that the presence of these reinforcement results in finer grains due to adequate compaction, which resulted from the sintering operation [15]. The pores seen in the sintered composites can be as attributed to different sizes of the particles contained in the composites. Further, an increased quantity of grain boundaries seen in the micrographs could result from decreased grain size due to high energy milling technique adopted for dispersion. The reinforcements which are evenly dispersed in the matrix could also be attributed to adequate milling time and speed employed during the milling/alloying of the powders. A detailed SEM image of the micrographs has been reported in a previous investigation by Akinwamide et al. [16].

\subsection{Potentiodynamic polarization}

The initiation and growth of pits on the composites surface during exposure to aggressive ions, and the repassivation of disrupted oxide films present on the surface of aluminumbased composites is associated with metastable pitting. The formation of pits on aluminium composites is a vital reaction that helps assess the resistance of the specimens to corrosion. The potentiodynamic polarization plots for sintered specimens are presented in Figure 2. It is evident that the highest corrosion density of $7.10 \mu \mathrm{A}$ is seen in pure aluminium, while the specimen incorporated with $2 \% \mathrm{TiFe}$ reinforcement is seen to have the lowest current density of $2.57 \mu \mathrm{A}$ and the highest corrosion potential of $-0.660 \mathrm{~V}$ in comparison to other sintered composites. The current densities and corrosion potentials of the specimens were also seen to decrease and increase, respectively, with increased volume percent of SiC. A similar observation was 

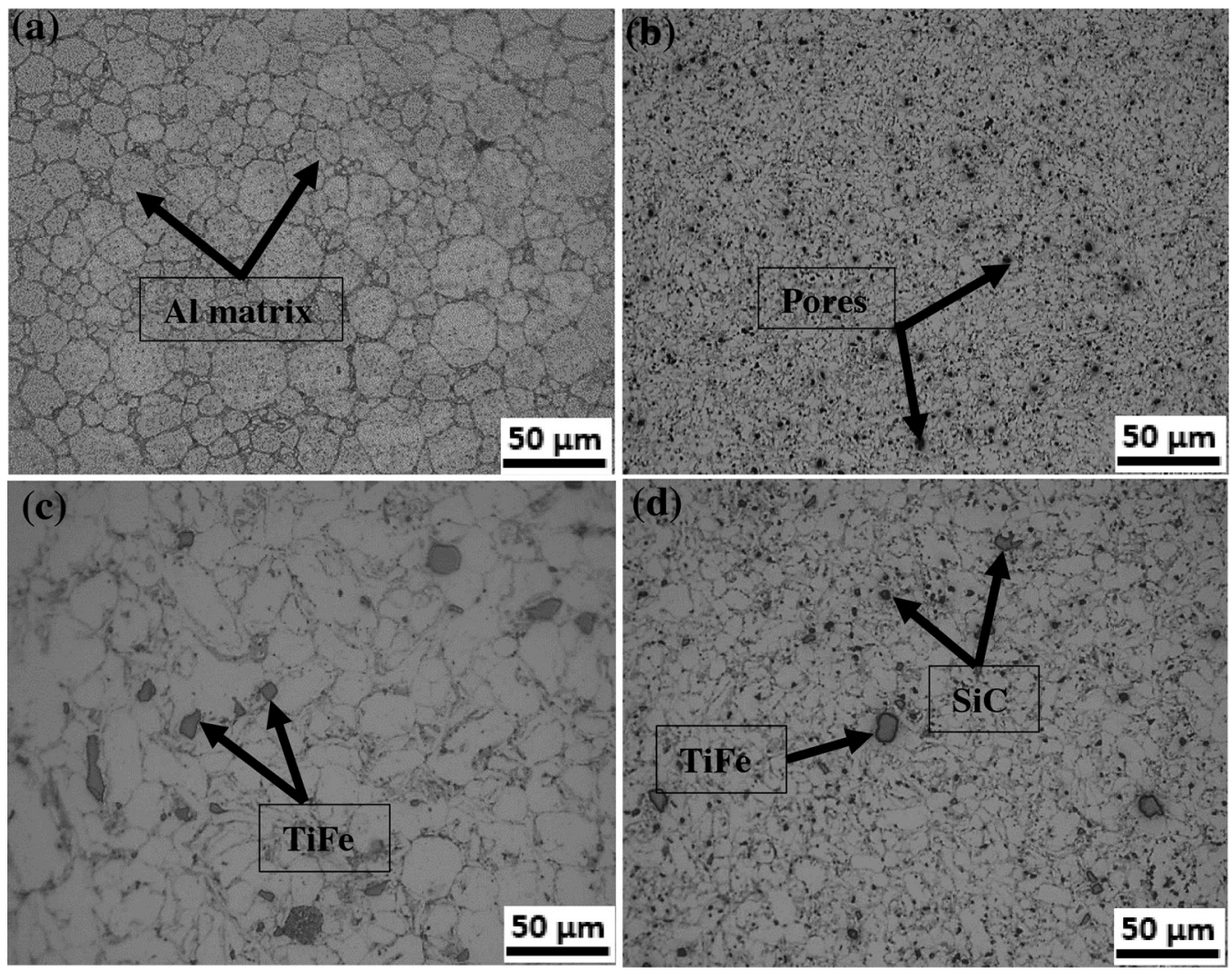

Fig. 1. Optical micrographs of (a) Pure aluminium (b) $\mathrm{Al}+2 \% \mathrm{SiC}$ (c) $\mathrm{Al}+2 \% \mathrm{TiFe}(\mathrm{d}) \mathrm{Al}+2 \% \mathrm{TiFe}+2 \% \mathrm{SiC}$.

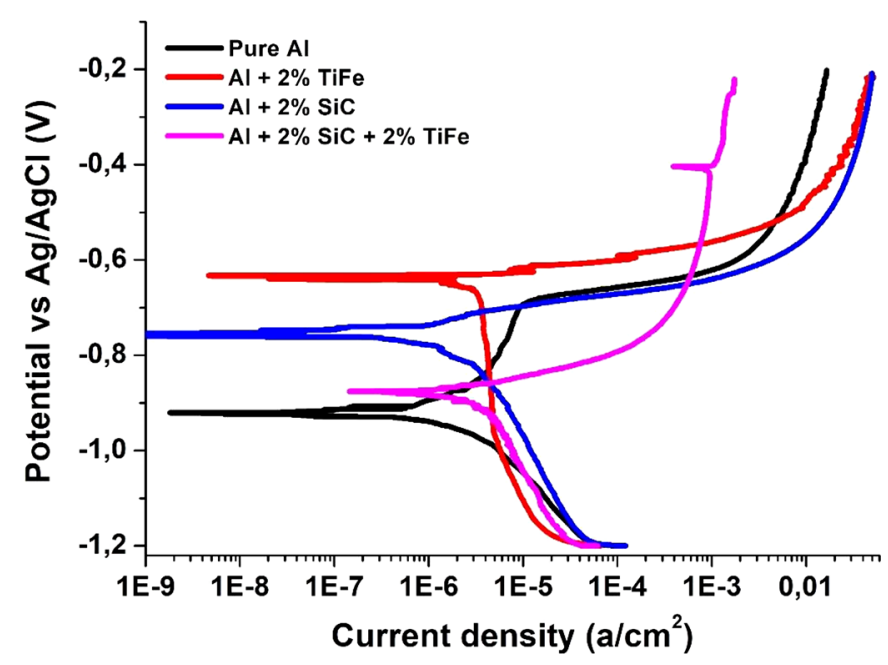

Fig. 2. Potentiodynamic polarization curves for sintered pure aluminium and composites.

reported in a study by Akinwamide et al. [14]. However, the samples incorporated with $2 \% \mathrm{SiC}$ also exhibited a reduced thermodynamic tendency to corrode, from the sufficiently formed passive oxide layers on the sample's surface. The rapid formation of passive layers can be ascribed to the corrosion inhibiting effect of titanium, which is present in the ferrotitanium reinforcement. A related report was given in an investigation by Perez et al. [17]. The increased current density $(7.10 \mu)$ in addition to a decreased corrosion potential $(-0.968 \mathrm{~V})$ seen in the pure aluminium specimen could be as a result of chloride reactions, which resulted in formation of soluble aluminium hydroxide (according to Eqs. (1)-(3)) [18], which prevents the stability of oxide formed on the surface of pure aluminium specimen $[14,19]$.

Furthermore, the fabricated composites are also observed to have been attacked by the aggressive chloride ions present in the electrolyte. This attack rapidly weakens the passive films formed on the specimen surface and also causes pitting corrosion due to the formation of intermetallic or secondary precipitates. However, the formed precipitates are susceptible to localized corrosion at grain boundaries [20,21]. An improved corrosion resistance exhibited by the binary alloys compared to the ternary alloy could be due to the cathodic reaction mechanism, which occurs during the pitting corrosion of aluminium composites in the chloride electrolyte.

$$
\begin{gathered}
\mathrm{Al}+3 \mathrm{H}_{2} \mathrm{O} \rightarrow \mathrm{Al}(\mathrm{OH})_{3}+3 \mathrm{H}^{+}+3 \mathrm{e}^{-} \\
\mathrm{Al}+2 \mathrm{H}_{2} \mathrm{O} \rightarrow \mathrm{AlO}(\mathrm{OH})+3 \mathrm{H}^{+}+3 \mathrm{e}^{-} \\
\mathrm{Al}+\frac{3}{2} \mathrm{H}_{2} \mathrm{O} \rightarrow \mathrm{Al}_{2} \mathrm{O}_{3}+3 \mathrm{H}^{+}+3 \mathrm{e}^{-}
\end{gathered}
$$


Table 2. Tafel properties of pure aluminium and composites.

\begin{tabular}{lllll}
\hline Specimen & $I_{\text {corr }}(\mu \mathrm{m})$ & $E_{\text {corr }}(\mathrm{V})$ & Cathodic beta $(\mathrm{V})$ & Anodic beta $(\mathrm{V})$ \\
\hline Pure $\mathrm{Al}$ & 7.10 & -0.968 & 0.185 & 0.144 \\
$\mathrm{Al}+2 \% \mathrm{TiFe}$ & 2.57 & -0.660 & 10.40 & 0.040 \\
$\mathrm{Al}+2 \% \mathrm{SiC}$ & 2.90 & -0.817 & 0.91 & 0.066 \\
$\mathrm{Al}+2 \% \mathrm{TiFe}+2 \% \mathrm{SiC}$ & 4.19 & -0.917 & 0.143 & 0.121 \\
\hline
\end{tabular}

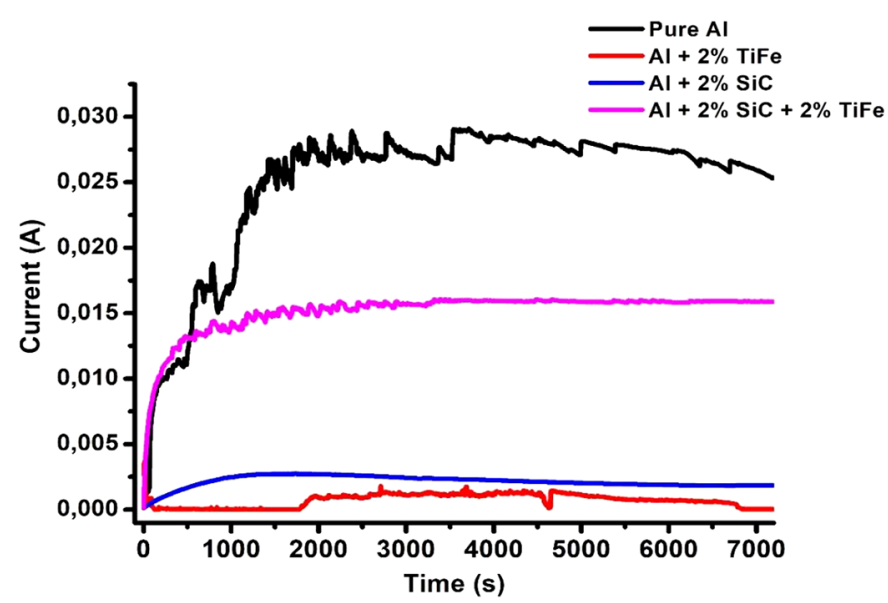

Fig. 3. Potentiostatic plot of pure aluminium and sintered composites.

The rapid deterioration observed in pure aluminium, and the specimen with reinforcement addition of $2 \%$ $\mathrm{SiC}+2 \% \mathrm{TiFe}$ particles can be ascribed to an increase in the formation of pits, which delayed the rate at which the passive protective films are formed on the surface of the specimens. The improved corrosion resistance exhibited by the binary aluminium alloys could also result from the preferential corrosion at the interfaces of the $\mathrm{Al} / \mathrm{SiC} / \mathrm{TiFe}$ interfaces. This is a major reason why the choice of reinforcement particles remains essential during the fabrication of aluminium matrix composites. Reports have shown that aluminium composites become susceptible to galvanic corrosion due to the difference in the potentials of the aluminium matrix and the respective reinforcements [22-24]. The values seen from the Tafel fit of the potentiodynamic polarization curves of the samples are presented in Table 2.

\subsection{Potentiostatic polarization}

Shown in Figure 3 are the potentiostaic plots for sintered specimens in the chloride electrolyte. The specimens exhibited different curves, indicating that the specimens react differently in the aggressive media. The binary alloys showed a continous stability in the test medium throughout the test, while the pure aluminium and composite reinforced with $\mathrm{Al}+2 \% \mathrm{SiC}+2 \% \mathrm{TiFe}$ attained stability after the first $1000 \mathrm{~s}$. The initial fluctuations visible from the binary alloy can be attributed to the formation of passive films due to the presence of the single reinforcements of TiFe and $\mathrm{SiC}$ particles [25]. Further observation shows that the pure aluminium and the ternary alloy show an increased current density, indicating a reduced decrease to corrosion resistance. In contrast, the binary alloys exhibit a reduced current density. This also shows an improved corrosion resistance of the binary alloys [26]. The rapid deposition of the passive layer, which led to stability from the initiation till the end of the test, results from the balanced proportion of $\mathrm{SiC}$ and $\mathrm{TiFe}$ reinforcement particles in the aluminium matrix. Hence, it is not difficult to imagine that the growth of the deposited oxide film on the specimen's surface and its current density will proceed at a slower rate [27].

\subsection{Micrographs of the corroded specimens}

The SEM morphologies of the corroded specimens after potentiodynamic polarization tests are presented in Figure 4. From Figure 4a, even distribution and formation of corrosion deposits on preferential sites are evident. The dissolution of the oxide/metal interface, which produces a localized aggressive environment, can increase the rate at which blisters are formed on the aluminium matrix beneath the oxide passive layer [28]. Figure $4 \mathrm{~b}$ also shows less attack on the specimen due to the dispersion of the silicon carbide particles in the matrix, thereby preventing the dissolution of the composite by the aggressive ions available in the test chloride medium [29]. In addition, the specimen with the incorporation of silicon carbide and ferrotitanium in Figure $4 \mathrm{c}$ reveals the presence of cracks and severe degradation of the specimen surface. This could be attributed to the higher volume percentage of the $\mathrm{SiC}$ particles present in the aluminum matrix [30]. The evidence of pits seen on the corroded surface of the reinforced specimens shows that the specimens are susceptible to intergranular attack [31].

The effect of mechanical attrition (milling) on grain refinement in aluminium matrix composites has been studied $[32,33]$. The grains of aluminium matrix composites are reportedly reduced to about $9 \mathrm{~nm}$ for body-centered cubic metals. In comparison, a reduction of about $13 \mathrm{~nm}$ is achievable in hexagonal close-packed and face-centered cubic metals. Therefore, the overall improvement in the corrosion resistance of the composites compared to the pure aluminium specimen can be ascribed to the grain refinement resulting from the high-energy ball milling 

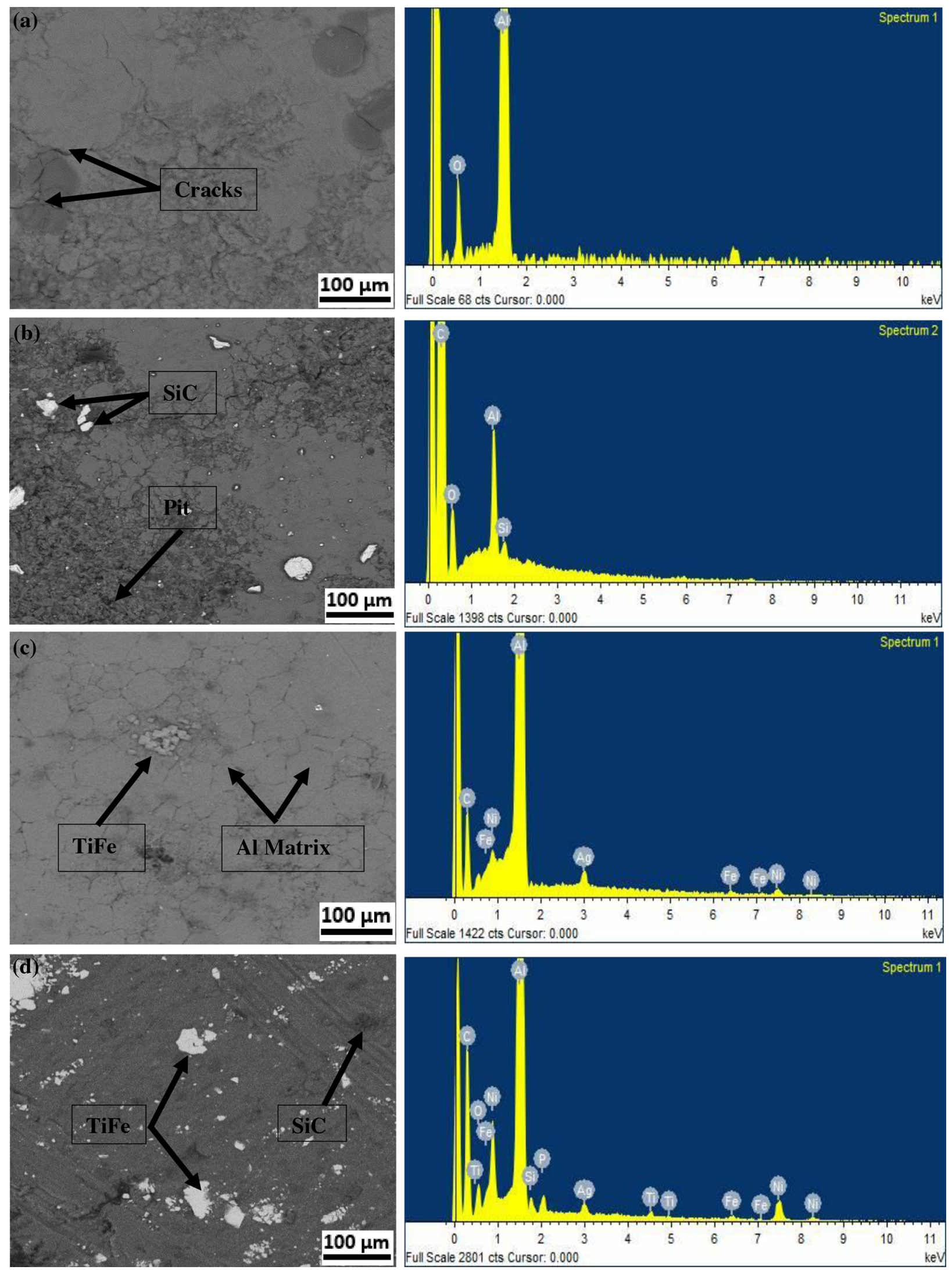

Fig. 4. $\mathrm{SEM}$ images of sintered (a) pure aluminium (b) $\mathrm{Al}+2 \% \mathrm{SiC}$ (c) $\mathrm{Al}+5 \% \mathrm{TiFe}(\mathrm{d}) \mathrm{Al}+5 \% \mathrm{SiC}+2 \% \mathrm{TiFe}$. 
technique adopted for dispersing the reinforcement particles within the aluminium matrix.

\section{Conclusion}

The corrosion behavior of sintered pure aluminium and composites incorporated with particles of TiFe and $\mathrm{SiC}$ was studied. The homogeneous dispersion of the particles within the matrix of aluminium was ascribed to factors that include sufficient milling speed, milling time, and fabrication technique. The potentiodynamic and potentiostaic polarization techniques showed that the binary alloys' corrosion resistance was improved compared to the ternary alloys. However, this improvement was attributed to the rapid repassivation of oxide films on the surface of the specimens, which resulted from the presence of incorporated particles. Post-corrosion observation of the surface of the specimen under SEM revealed pits and cracks, which resulted from the effect of aggressive chloride ions present in the test electrolyte. Overall, the incorporation of $\mathrm{SiC}$ and TiFe reinforcement particles was seen to improve the corrosion resistance of the sintered aluminium composites in comparison to the pure aluminium specimen.

The National Research Foundation, South Africa is appreciated for providing the funds used for this research.

\section{References}

1. S.O. Akinwamide, Study of microstructural and mechanical properties of stir cast $\mathrm{Al}$ ( $\mathrm{SiC}-\mathrm{Mg}-\mathrm{TiFe})$ composite, Fluid Dyn. Mater. Process. 15 (2019) 15-26

2. B. Bobić, S. Mitrović, M. Babić, I. Bobić, Corrosion of metalmatrix composites with aluminium alloy substrate, Tribol. Ind. 32 (2010) 3-11

3. I.A. Kartsonakis, E.P. Koumoulos, C.A. Charitidis, Advancement in corrosion resistance of AA 2024-T3 through sol-gel coatings including nanocontainers, Manufactur. Rev. 4 (2017) 2

4. S.O. Akinwamide, S.M. Lemika, B.A. Obadele, O.J. Akinribide, B.T. Abe, P.A. Olubambi, Characterization and mechanical response of novel Al-(Mg-TiFe-SiC) metal matrix composites developed by stir casting technique, J. Compos. Mater. (2019) 0021998319851198

5. K. Shirvanimoghaddam, H. Khayyam, H. Abdizadeh, M.K. Akbari, A. Pakseresht, F. Abdi, A. Abbasi, M. Naebe, Effect of $\mathrm{B} 4 \mathrm{C}$, TiB2 and $\mathrm{ZrSiO} 4$ ceramic particles on mechanical properties of aluminium matrix composites: experimental investigation and predictive modelling, Ceramics Int. 42 (2016) 6206-6220

6. R. Rosliza, Improvement of corrosion resistance of aluminium alloy by natural products, InTech, 2012

7. S.E. Vannan, S.P. Vizhian, Microstructure and mechanical properties of as cast aluminium alloy 7075 /basalt dispersed metal matrix composites, J. Miner. Mater. Character. Eng. 2 (2014) 182

8. B. Subramaniam, B. Natarajan, B. Kaliyaperumal, S.J.S. Chelladurai, Investigation on mechanical properties of aluminium 7075-boron carbide-coconut shell fly ash reinforced hybrid metal matrix composites, China Foundry 15 (2018) 449-456

9. A.V. Muley, S. Aravindan, I. Singh, Nano and hybrid aluminum based metal matrix composites: an overview, Manufactur. Rev. 2 (2015) 15

10. C. Shearwood, Y.Q. Fu, L. Yu, K.A. Khor, Spark plasma sintering of TiNi nano-powder, Scr. Mater. 52 (2005) $455-460$

11. S.O. Akinwamide, N. Tshabalala, O.E. Falodun, S.R. Oke, O.J. Akinribide, B.T. Abe, P.A. Olubambi, Microstructural and corrosion resistance study of sintered Al-tin in sodium chloride solution, Mater. Today: Proc. 18 (2019) $2881-2886$

12. N. Saheb, Z. Iqbal, A. Khalil, A.S. Hakeem, N. Al Aqeeli, T. Laoui, A. Al-Qutub, R. Kirchner, Spark plasma sintering of metals and metal matrix nanocomposites: a review, J. Nanomater. 2012 (2012) 18

13. H. Zakaria, Microstructural and corrosion behavior of $\mathrm{Al} / \mathrm{SiC}$ metal matrix composites, Ain Shams Eng. J. 5 (2014) 831-838

14. S.O. Akinwamide, S.M. Lemika, F. Adams, O.J. Akinribide, B.T. Abe, P.A. Olubambi, An investigation on the corrosion behavior of $\mathrm{Al}(\mathrm{Mg}$-TiFe-SiC) matrix composite in acidic and chloride media, Mater. Today: Proc. 18 (2019) 3827-3834

15. A. Gokce, F. Findik, Mechanical and physical properties of sintered aluminum powders, J. Achiev. Mater. Manufactur. Eng. 30 (2008) 157-164

16. S.O. Akinwamide, M. Lesufi, O.J. Akinribide, P. Mpolo, P.A. Olubambi, Evaluation of microstructural and nanomechanical performance of spark plasma sintered TiFe-SiC reinforced aluminium matrix composites, J. Mater. Res. Technol. 9 (2020) 12137-12148

17. O.R. Pérez, J. García-Hinojosa, F.R. Gómez, S. MejiaSintillo, V. Salinas-Bravo, R. Lopes-Sesenez, J. GonzalezRodriguez, C.A. Garcia-Pérez, Corrosion behavior of A356/ $\mathrm{SiC}$ alloy matrix composites in $3.5 \% \mathrm{NaCl}$ solution, Int. J. Electrochem. Sci. 14 (2019) 7423-7436

18. R. Gundersen, K. Nisancioglu, Cathodic protection of aluminum in seawater, Corrosion 46 (1990) 279-285

19. P. Natishan, W. O'grady, Chloride ion interactions with oxide-covered aluminum leading to pitting corrosion: a review, J. Electrochem. Soc. 161 (2014) C421

20. P. Marcus, V. Maurice, H.-H. Strehblow, Localized corrosion (pitting): a model of passivity breakdown including the role of the oxide layer nanostructure, Corros. Sci. 50 (2008) 2698-2704

21. G. Frankel, N. Sridhar, Understanding localized corrosion, Mater. Today 11 (2008) 38-44

22. I. Gurrappa, V.B. Prasad, Corrosion characteristics of aluminium based metal matrix composites, Mater. Sci. Technol. 22 (2006) 115-122

23. S. Payan, Y. Le Petitcorps, J.-M. Olive, H. Saadaoui, Experimental procedure to analyse the corrosion mechanisms at the carbon/aluminium interface in composite materials, Compos. A: Appl. Sci. Manufactur. 32 (2001) 585-589

24. S.O. Akinwamide, O.J. Akinribide, P.A. Olubambi, Influence of ferrotitanium and silicon carbide addition on structural modification, nanohardness and corrosion behaviour of stircast aluminium matrix composites, Silicon (2020) 1-12

25. M.S.B. Selamat, Corrosion behavior of $\mathrm{SiC} \mathrm{p} / 6061 \mathrm{Al}$ metal matrix composites in chloride solutions, Adv. Perform. Mater. 3 (1996) 183-204 
26. S.O. Akinwamide, O.J. Akinribide, P.A. Olubambi, Microstructural evolution, mechanical and nanoindentation studies of stir cast binary and ternary aluminium based composites, J. Alloys Comp. (2020) 156586

27. G.M. Pinto, J. Nayak, A.N. Shetty, Corrosion behaviour of 6061 Al-15vol. Pct. SiC composite and its base alloy in a mixture of 1: 1 Hydrochloric and sulphuric acid medium, Int. J. Electrochem. Sci. 4 (2009) 1452-1468

28. G.P. Kumar, R. Keshavamurthy, P. Kumari, C. Dubey, Corrosion behaviour of TiB2 reinforced aluminium based in situ metal matrix composites, Persp. Sci. 8 (2016) 172-175

29. M.M. Boopathi, K. Arulshri, N. Iyandurai, Evaluation of mechanical properties of aluminium alloy 2024 reinforced with silicon carbide and fly ash hybrid metal matrix composites, Am. J. Appl. Sci. 10 (2013) 219
30. A. Pardo, M. Merino, S. Merino, F. Viejo, M. Carboneras, R. Arrabal, Influence of reinforcement proportion and matrix composition on pitting corrosion behaviour of cast aluminium matrix composites (A3xx. x/SiCp), Corros. Sci. 47 (2005) 1750-1764

31. Z. Ahmad, P. Paulette, B.A. Aleem, Mechanism of localized corrosion of aluminum-silicon carbide composites in a chloride containing environment, J. Mater. Sci. 35 (2000) 2573-2579

32. K. Ralston, N. Birbilis, Effect of grain size on corrosion: a review, Corrosion 66 (2010) 075005-075005-075013

33. M. Orłowska, E. Ura-Binczyk, L. Olejnik, M. Lewandowska, The effect of grain size and grain boundary misorientation on the corrosion resistance of commercially pure aluminium, Corros. Sci. 148 (2019) 57-70

Cite this article as: Samuel Olukayode Akinwamide, Miltia Lesufi, Ojo Jeremiah Akinribide, Bukola Joseph Babalola, Peter Apata Olubambi, Studies on corrosion behaviour of sintered aluminium based composites in chloride environment, Manufacturing Rev. 8, $22(2021)$ 